\title{
Identification and characterization of the intracellular poly-3-hydroxybutyrate depolymerase enzyme PhaZ of Sinorhizobium meliloti
}

\author{
Maria A Trainer1,2, David Capstick1,3, Alicja Zachertowska1, Kathy N Lam¹,4, Scott RD Clark1 and Trevor C Charles*1
}

\begin{abstract}
Background: S. meliloti forms indeterminate nodules on the roots of its host plant alfalfa (Medicago sativa). Bacteroids of indeterminate nodules are terminally differentiated and, unlike their non-terminally differentiated counterparts in determinate nodules, do not accumulate large quantities of Poly-3-hydroxybutyrate (PHB) during symbiosis. PhaZ is in intracellular PHB depolymerase; it represents the first enzyme in the degradative arm of the PHB cycle in S. meliloti and is the only enzyme in this half of the PHB cycle that remains uncharacterized.

Results: The S. meliloti phaZ gene was identified by in silico analysis, the ORF was cloned, and a S. meliloti phaZ mutant was constructed. This mutant exhibited increased PHB accumulation during free-living growth, even when grown under non-PHB-inducing conditions. The phaZ mutant demonstrated no reduction in symbiotic capacity; interestingly, analysis of the bacteroids showed that this mutant also accumulated PHB during symbiosis. This mutant also exhibited a decreased capacity to tolerate long-term carbon starvation, comparable to that of other PHB cycle mutants. In contrast to other PHB cycle mutants, the S. meliloti phaZ mutant did not exhibit any decrease in rhizosphere competitiveness; however, this mutant did exhibit a significant increase in succinoglycan biosynthesis.

Conclusions: $S$. meliloti bacteroids retain the capacity to synthesize PHB during symbiosis; interestingly, accumulation does not occur at the expense of symbiotic performance. phaZ mutants are not compromised in their capacity to compete for nodulation in the rhizosphere, perhaps due to increased succinoglycan production resulting from upregulation of the succinoglycan biosynthetic pathway. The reduced survival capacity of free-living cells unable to access their accumulated stores of PHB suggests that PHB is a crucial metabolite under adverse conditions.
\end{abstract}

\section{Background}

Several genera of soil bacteria can enter into nitrogen-fixing symbioses with leguminous plants. These genera, commonly referred to as the 'rhizobia', include Sinorhizobium, Rhizobium, Bradyrhizobium, and Azorhizobium. Formation of specialized, microaerophilic nodules on the roots of the host plant are elicited by the bacteria. Following infection and colonization of the nodule tissue, the bacteria undergo differentiation into a mature state known as the bacteroid, which can reduce atmospheric dinitrogen to ammonia. Bacteroid metabolism is dominated by the production of fixed nitrogen, which is transferred directly to the host plant. This energetically

*Correspondence: tcharles@uwaterloo.ca

1 Department of Biology, University of Waterloo, 200 University Ave W, Waterloo, ON N2L 3G1, Canada

Full list of author information is available at the end of the article expensive reaction, catalyzed by the nitrogenase complex, is fuelled by the host plant by provision of fixed carbon, generally in the form of C4-dicarboxylates such as malate and succinate [1-3]. Most of the carbon supplied by the plant is used to fuel nitrogen fixation, however, under certain circumstances, some of the carbon appears to be diverted by the bacteroid into the production of intracellular carbon storage polymers such as poly-3-hydroxybutyrate (PHB). This is a characteristic of bacteroids found in determinate nodules but not of indeterminate nodules (reviewed in [4]). Within the bacteroid, PHB deposits can be visualized as defined, electron-transparent granules located within the cytoplasm [5-7].

S. meliloti forms indeterminate nodules on the roots of its host plant alfalfa (Medicago sativa). These nodules are characterized by the existence of a persistent apical meristem and an elongated morphology. Within the nodule, 
the bacteroids persist and progress through defined zones of bacteroid differentiation [8]. Indeed, loss of PHB granules from the cytoplasm of the bacteria invading indeterminate nodules is a well-documented phenomenon that occurs at a specific point within bacteroid development [9].

Bacteroids of indeterminate nodules undergo such large physiological and metabolic changes relative to those of determinate nodules [10] that, until recently, it was unclear whether mature bacteroids within indeterminate nodules retained the capacity to synthesize and store PHB. A recent study [11] clearly demonstrated that bacteroids of $R$. leguminosarum bv. viciae, which forms indeterminate nodules on pea plants, retain the capacity to synthesize and store large quantities of PHB but only when carbon supply is in excess and bacteroid metabolism is limited by the availability of a key nutrient (reviewed in [4]). During saprophytic growth, PHB accumulation occurs during periods of nutrient deprivation when carbon is in excess. This strategy is employed by many species of bacteria. The first step in PHB degradation is catalyzed by a substrate-specific depolymerase. PHB undergoes a transition from an amorphous granule in the intracellular state to a denatured semi-crystalline form upon release into the environment. As a result, different PHB depolymerases are employed depending on the nature of the substrate. While extracellular depolymerases have been identified and characterized in a wide variety of bacteria, very little is yet known about their intracellular counterparts. To date, only a handful of intracellular PHB depolymerases have been reported in the literature, most of which appear to lack the typical lipase box motif (Gly-X-Ser-X-Gly) associated with extracellular PHB depolymerases [12-17]. While the enzymes responsible for the synthesis and storage of PHB have been characterized in a wide variety of bacteria, including the rhizobia (reviewed in [4]), only a few studies have investigated the role of intracellular PHB depolymerases and, to date, no studies have reported the characterization of a rhizobial PHB depolymerase.

Here we report the cloning and characterization of PhaZ from S. meliloti after its identification as the putative intracellular PHB depolymerase based on in silico analyses of the genome sequence and comparisons to other intracellular PHB depolymerase sequences. This work is the first report of a PHB depolymerase mutant in S. meliloti and, indeed, in the rhizobia. This work also represents the final step in genetic characterization of the complete PHB cycle in these bacteria, as all other enzymes of both the synthetic and degradative pathways have been previously studied $[3,5,6,8,18,19]$. To the best of our knowledge, this work also documents the first confirmed example of the presence of intracellular $\mathrm{PHB}$ granules in $\mathrm{N}_{2}$-fixing bacteroids of $S$. meliloti.

\section{Results and Discussion}

Identification of the S. meliloti phaZ Open Reading Frame and Construction of an S. meliloti phaZ mutant

The phaZ gene was identified as a 1272 bp open reading frame SMc02770 in the S. meliloti genome sequence [20] by comparison to phaZ of Cupriavidus necator [13]. The amino acid sequences of these two proteins share $51 \%$ identity. Interestingly, like phaZ of C. necator, the PhaZ protein of S. meliloti does not possess a Gly-X-Ser-X-Gly lipase box motif [21] that is characteristic of many extracellular PHB depolymerases. The absence of this motif implies that these intracellular PhaZ homologues may use a different active site structure to extracellular PHB depolymerases. Primers were designed to internal regions of phaZ to amplify a fragment (from S35 to F292) by PCR, and the resultant 835 bp fragment was cloned into pGEM ${ }^{\circ}$-T Easy (Promega) to generate pAZ101. An internal disruption of the cloned phaZ fragment was generated by introducing a $\Omega \mathrm{SmSp}$ cassette as a Cfr91 fragment into the unique KpnI site at 299 bp to yield pAZ102. The phaZ:: $\Omega$ SmSp was subsequently excised as an EcoRI fragment and subcloned into pK19mobsacB to give pAZ103. pAZ103 was introduced into S. meliloti Rm5000 by triparental mating using E. coli MT616 as a helper strain. Single recombinants were identified by selecting for $\mathrm{Rf}^{R}, \mathrm{Sm}^{R}, \mathrm{Sp}^{R}$ transconjugants. Putative double recombinants were identified by plating onto TY Sm Sp Sucrose (5\%). Subsequent screening for loss of vector-encoded $\mathrm{Nm}^{R}$ confirmed the loss of $\mathrm{pK} 19$ mobsacB. The resultant $\mathrm{Rf}^{R}, \quad \mathrm{Sm}^{R}, \quad \mathrm{Sp}^{R}, \quad \mathrm{Nm}^{S}$ phaZ mutant was designated Rm11417. The mutagenesis was confirmed by Southern blot using the phaZ PCR product as a probe. The probe hybridized to a $1.55 \mathrm{~kb}$ EcoRI fragment of genomic DNA in the wild-type strain Rm5000, and to a $3.55 \mathrm{~kb}$ fragment in Rm11417, confirming the presence of the $2 \mathrm{~kb} \Omega \mathrm{SmSp}$ cassette (data not shown). This mutation was transduced into Rm1021 using the $\varphi \mathrm{M} 12$ phage by standard techniques [22] and the resultant mutant was designated Rm11430.

\section{Cloning of phaZ gene for complementation assays} Primers Smc02770F 5'-CCTAAGCTTATGTTCTACCAGCTTTACGAGATGAAC-3' and Smc02770R 5'CGAAAGCTTTTAGTGATGGTGATGGTGATGGGCCGACTTGCCGCCCTTG-3' were designed to the $5^{\prime}$ and 3 ' regions of SMc02770, incorporating HindIII sites into the $5^{\prime}$ and $3^{\prime}$ ends as well as a $3^{\prime}$ terminal His tag. The PCR product was cloned as a HindIII fragment into pRK7813 and the resultant construct was named pMA157. This construct was introduced into Rm11430 by triparental conjugation using MT616 as the mobilizer strain. 
Growth Phenotype of Rm11430 and ability to survive longterm carbon starvation

Mutants of phaC, phaB, and $b d h A$ all demonstrate impaired growth on PHB cycle intermediates [23,24]. To determine if a lesion in $p h a Z$ resulted in a similar impairment in the capacity of S. meliloti to utilize PHB Cycle intermediates, the growth of Rm11430 was compared to that of Rm1021, Rm11105 [23], Rm11107 [23] and Rm11347 [24] on TY, YMA, and minimal media containing either $15 \mathrm{mM}$ acetate (A), acetoacetate (AA) or D-3hydroxybutyrate (HB) as sole carbon sources. No difference in growth phenotype was observed between Rm11430 and Rm1021 (Table 1).

The ability of the phaZ mutant strain to withstand long-term carbon starvation was tested, relative to both Rm1021 and Rm11105, by incubation for 4 weeks in M9 liquid medium with no added carbon source. Cells were grown to late-log in YMB and washed twice in M9. A 1:50 dilution was used to inoculate $75 \mathrm{ml}$ of M9 salts. Starting $\mathrm{cfu} / \mathrm{ml}$ was determined immediately following inoculation by serial dilution of a $1 \mathrm{ml}$ aliquot. Starting cultures typically contained approximately $2 \times 10^{5} \mathrm{cfu} / \mathrm{ml}$. These starting values were each given a relative value of $1.1 \mathrm{ml}$ samples were removed at 7 day intervals and serial dilutions were used to determine $\mathrm{cfu} / \mathrm{ml}$. Values presented are the averages of 3 independent cultures. The data in Figure. 1 show that the ability to synthesize and/or break down PHB has a significant impact on long-term survival in the absence of an exogenous carbon source. The wildtype strain $\mathrm{Rm} 1021$ is capable of increasing cell density during the early stages of starvation, presumably by degrading readily mobilizable intracellular carbon stores, a pattern which is not seen in either the phaZ or phaC mutants.

\section{PHB accumulation}

To assess the effect of the phaZ lesion on PHB content in Rm11430, total PHB accumulation of stationary-phase cells was measured and compared to the wild-type strain

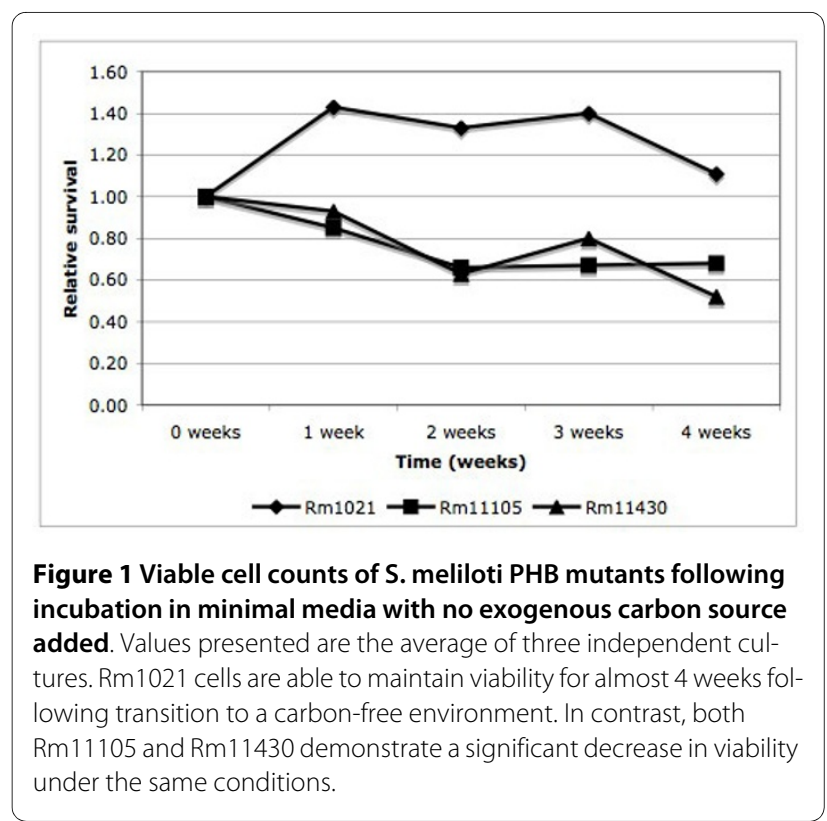

Rm1021. Cells were grown to stationary phase in either YMB and the accumulated PHB was measured as a total cellular dry weight $(\% \mathrm{w} / \mathrm{w})$. These data are shown in Table 2 and represent the average from three samples. Rm11430 demonstrates significantly increased PHB accumulation relative to $\mathrm{Rm} 1021$ suggesting that, while synthesis of PHB is not impaired, the lesion in phaZ inhibits degradation of PHB. The PHB accumulation phenotype of Rm11430 is complemented by pMA157, demonstrating a clear relationship between the presence of phaZ and PHB accumulation.

\section{Effect on expression of succinoglycan synthesis genes}

The product of the exoF gene is involved in the transfer of the first sugar, galactose, to the lipid carrier, upon which the subunits of succinoglycan are assembled [25]. pD82exoF::TnphoA was constructed by homologous recombination between exoF carried on pD82 [26] and the chromosomal exoF::TnphoA fusion of strain Rm8369

Table 1: Growth Phenotypes of S. meliloti PHB Cycle Mutants

\begin{tabular}{|c|c|c|c|c|c|c|}
\hline Strain & $\begin{array}{l}\text { Relevant } \\
\text { Characteristics }\end{array}$ & YMA Phenotype & \multicolumn{4}{|c|}{ Carbon Source Utilization } \\
\hline Rm1021 & wild-type & Mucoid & + & + & + & + \\
\hline Rm11107 & $b d h A:: \operatorname{Tn} 5$ & Mucoid & + & - & + & + \\
\hline Rm11347 & phaB $\Omega$ & Dry & + & - & + & - \\
\hline $\mathrm{Rm} 11430$ & phaZSSmSp & Mucoid & + & + & + & + \\
\hline
\end{tabular}


Table 2: PHB accumulation during free-living growth in Yeast-Mannitol Medium

\begin{tabular}{lll}
\hline Strain & Relevant Characteristics & PHB Accumulation \% cell dry mass \\
\hline Rm1021 & wild-type & 18.9 \\
$\operatorname{Rm} 11105$ & phaC::Tn5 & 0.240 \\
$\operatorname{Rm} 11430$ & phaZSSmSp & 28.6 \\
Rm11430 pMA157 & phaZSSmSp pRK7813 phaZ & 7.39 \\
\hline
\end{tabular}

[27]. The resultant plasmid was used to measure the transcriptional activity of exoF in different S. meliloti PHB mutant backgrounds when grown under different culture conditions. A Student's t-test was used to analyze the data and determine statistical significance of the observed differences. The results presented in Table 3 represent the mean of three independent samples. When analyzed using a two-tailed Student's t-test, the 1.1-fold increase in exoF expression exhibited by YMB-grown Rm11430 is statistically significant. Furthermore, the non-mucoid mutants Rm11105 and Rm11107 exhibit a reduction in exoF expression. This is consistent with the observation that colonies formed by Rm11430 appear larger and more mucoid on YMA than Rm11105 or Rm11107 (Table 1).

\section{Symbiotic phenotype of Rm1 1430 and bacteroid PHB accumulation}

Unlike bacteroids of determinate nodules, bacteroids of $S$. meliloti do not accumulate PHB during symbiosis (reviewed in [4]). Interestingly, a mutant of $R$. leguminosarum unable to cycle amino acids between the bacteroid and plants, showed apparent accumulation of $\mathrm{PHB}$ in the bacteroid within pea indeterminate nodules [11]. This suggests that the pathway for PHB metabolism can function within bacteroids of indeterminate nodules; however accumulation of PHB only occurs under extreme circumstances for example, when carbon is in excess and bacteroid metabolism is limited by the availability of a key nutrient. To confirm that $S$. meliloti bacteroids are capable of PHB synthesis and accumulation, alfalfa nodules induced by $\mathrm{Rm} 11430$ were prepared, sectioned and analyzed by TEM. Figure 2(a) clearly shows that bacteroids of Rm11430 accumulate PHB during sym- biosis, with numerous, electron-transparent, PHB granules visible within the cytoplasm of the bacteroids when viewed by TEM. This is in contrast to bacteroids of Rm1021, shown in Figure 2(b), which demonstrate a notable absence of PHB.

Symbiotic assays with the host plant alfalfa revealed no significant difference between the phaZ mutant Rm11430 and the wild-type strain Rm1021. Plants inoculated with Rm11430 had an average shoot dry mass (SDM) of 10.56 $\mathrm{mg}$ compared to $10.80 \mathrm{mg}$ for plants inoculated with Rm1021, both of which were significantly different to the uninoculated controls, which had an average SDM of 4.16 $\mathrm{mg}$. This is interesting since it suggests that PHB accumulation, as confirmed in Figure 2, does not occur at the expense of symbiotic effectiveness.

\section{Competitiveness for nodule occupancy of Rm 11430}

The ability of $S$. meliloti $\mathrm{Rm} 11430$ to compete for nodule occupancy was assayed by co-inoculating alfalfa plants with different strain combinations. Table 4 shows that, when co-inoculated in approximately equal ratios with the wild-type strain, Rm11430 demonstrated no discernible difference in competitiveness relative to $\mathrm{Rm} 1021$. The percentage of $\mathrm{Rm} 11430$ in the original inoculum was similar to the percentage of nodules that it occupied. In agreement with previous studies [28], both Rm11105 (phaC) and Rm11107 (bdhA) demonstrated significantly reduced competitiveness relative to wild-type. Table 4 also shows that both Rm11105 and Rm11107 demonstrate reduced competitiveness relative to $\mathrm{Rm} 11430$, with the phaC phenotype being more pronounced than the $b d h A$ phenotype.

Table 3: exoF::phoA Alkaline Phosphatase Assay

\begin{tabular}{llll}
\hline Strain & Relevant Characteristics & Activity (U) & Std Error \\
\hline Rm1021 & wild-type & 14.1 & 0.331 \\
$\operatorname{Rm} 11105$ & phaC::Tn5 & $9.68^{a}$ & 0.264 \\
$\operatorname{Rm} 11347$ & phaBO & $6.23^{a}$ & 0.223 \\
$\operatorname{Rm} 11107$ & bdhA::Tn5 & 16.1 & 0.714 \\
$\operatorname{Rm} 11430$ & phaZOSmSp & $15.7^{a}$ & 0.296 \\
\hline
\end{tabular}

a These differences are statistically significant from the value recorded for Rm1021, when analysed using a two-tailed Student's t-test 


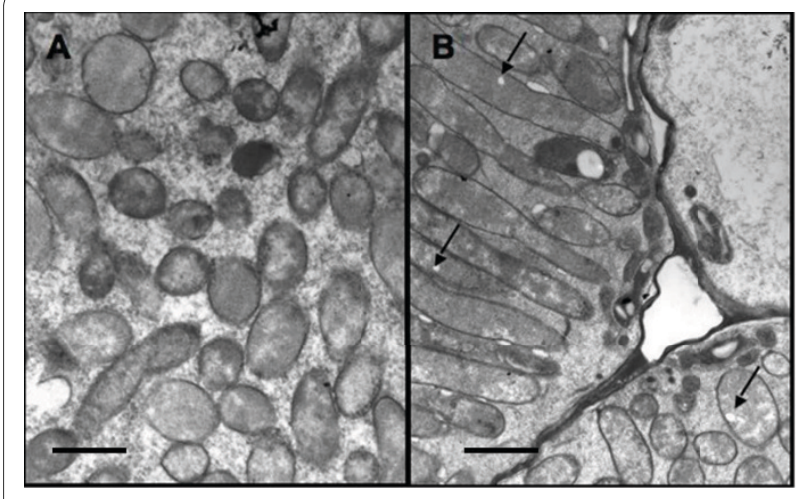

Figure 2 Bacteroids of $\mathrm{Rm} 1021$ (A) and $\mathrm{Rm} 11430$ (B). Electrontransparent PHB granules are clearly visible in bacteroids of Rm11430. PHB granules in the cytoplasm of the Rm11430 bacteroids are indicated in panel B. These granules are notably absent in the bacteroids of Rm1021 shown in panel A. Scale bar: $2 \mu \mathrm{m}$.

The role of EPS in the establishment of nitrogen-fixing symbioses between $S$. meliloti and $M$. sativa has long been acknowledged [29], but the precise mechanism of interaction remains elusive. Mutants unable to synthesize EPS are characteristically Fix-. The observation that phaC and phaB mutants of $S$. meliloti are still able to establish successful symbioses [24] suggests that synthesis of succinoglycan in these mutants, albeit at a reduced level, is still sufficient to facilitate nodulation. This is consistent with previous reports which suggest that the production of small amounts of low-molecular-weight (LMW) EPS is sufficient to establish a successful symbiosis [29]. Indeed, it is conceivable that the competition defect observed in phaC mutants of $S$. meliloti may be due to extremely low levels of succinoglycan production. The phaC mutant may produce sufficient succinoglycan to establish an effective symbiosis but, assuming that the succinoglycan itself is playing a role in signalling during early nodulation, not enough to allow it to compete with strains producing higher levels of the EPS. Interestingly, the phaZ mutant demonstrates wild-type competitiveness and is able to out-compete both the phaC and $b d h A$ mutants for nodulation. It is conceivable that another metabolic pathway that is dependent on D-3-HB metabolism may play a role in nodulation competitiveness. It is noteworthy that, although it has higher succinoglycan production than Rm1021, the phaZ mutant was not more competitive than the wild-type strain. While it is tempting to speculate that there may be a critical level of succinoglycan, above which, further gains in competitiveness are not seen, further information regarding the synthesis of succinoglycan during the infection process is still needed. Studies are currently underway in our lab to investigate this possibility further.

It is conceivable that, when PHB synthesis is inhibited, intermediates required for succinoglycan are not synthesized efficiently. It is also possible that, in the absence of a functional PHB synthesis pathway, enzymes required for

Table 4: Nodulation competitiveness of the S. meliloti wild-type strain and bdhA, phaC and phaZ mutants co-inoculated in the described ratios on $M$. sativa plants

\begin{tabular}{|c|c|c|c|c|}
\hline \multirow{2}{*}{$\begin{array}{l}\text { Strain (\%) in } \\
\text { inoculum }\end{array}$} & \multirow[t]{2}{*}{ No. nodules tested } & \multicolumn{3}{|c|}{ Nodule occupancy (\%) } \\
\hline & & Strain 1 & Strain 2 & Both \\
\hline $\begin{array}{l}R m 11430(60)+ \\
R m 1021(40)\end{array}$ & 18.0 & 61.1 & 22.2 & 16.7 \\
\hline $\begin{array}{l}\operatorname{Rm} 11430(91)+ \\
\operatorname{Rm} 1021(9)\end{array}$ & 15.0 & 93.3 & 6.7 & 0 \\
\hline $\begin{array}{l}\operatorname{Rm} 11430(54)+ \\
\operatorname{Rm} 11105 \text { (46) }\end{array}$ & 16.0 & 100 & 0 & 0 \\
\hline $\begin{array}{l}R m 11105(59)+ \\
R m 1021(41)\end{array}$ & 15.0 & 6.70 & 93.3 & 0 \\
\hline $\begin{array}{l}\operatorname{Rm} 11105(88)+ \\
\operatorname{Rm} 1021(12)\end{array}$ & 20.0 & 5.00 & 75.0 & 20.0 \\
\hline $\begin{array}{l}\operatorname{Rm} 11430(51)+ \\
\operatorname{Rm} 11107 \text { (49) }\end{array}$ & 20.0 & 65.0 & 35.0 & 0 \\
\hline $\begin{array}{l}R m 11107(49)+ \\
\operatorname{Rm} 1021(51)\end{array}$ & 14.0 & 21.4 & 78.6 & 0 \\
\hline $\begin{array}{l}\operatorname{Rm} 11107(77)+ \\
\operatorname{Rm} 1021(23)\end{array}$ & 15.0 & 86.7 & 0 & 13.3 \\
\hline $\begin{array}{l}R m 11107(44)+ \\
R m 11144(56)\end{array}$ & 19.0 & 94.7 & 0 & 5.30 \\
\hline
\end{tabular}


succinoglycan may be inhibited or down-regulated. Furthermore, it has been suggested that acetyl phosphate may provide a regulatory link between PHB and succinoglycan synthesis [30]. Studies in the thermophilic cyanobacterium Synechococcus sp. strain MA19, have shown that acetyl phosphate is involved in the post-translational regulation of PHB synthase in vitro, and that this regulation is concentration-dependent [30]. As well, that study revealed that the enzyme phosphotransacetylase, which converts acetyl-CoA to acetyl phosphate, is only active under PHB-accumulating conditions [30]. In E. coli, acetyl phosphate is known to act as a global signal which acts through two-component regulatory signals [31], perhaps by direct phosphorylation of the response regulator [32] itself. Furthermore, the ChvI protein, of the S. meliloti ExoS-ChvI two-component regulatory system, is able to autophosphorylate in the presence of acetyl phosphate in vitro [33]. Since PHB synthesis mutants may excrete excess acetyl-CoA, levels of acetyl phosphate will likely be low under these conditions. Therefore, intracellular levels of acetyl phosphate may be an important factor in the ExoS-ChvI-dependent regulation of succinoglycan synthesis.

\section{Conclusions}

Previous studies have demonstrated that the ability of certain bacteria to synthesize, accumulate and metabolize intracellular PHB stores is important in enhancing their capacity to survive unfavourable growth conditions [3437]. Rhizobia in the soil environment must contend with varying nutrient conditions, from the carbon-deficient bulk soil, to the carbon-rich rhizosphere [33]. The ability to accumulate and utilize carbon stores would be highly advantageous, allowing rhizobia to cope with fluctuating carbon conditions, and thus, make them more competitive against other bacterial populations [38]. Previous studies have shown that mutant strains of $S$. meliloti unable to synthesize $(p h a C)$ or degrade $(b d h A)$ PHB show a significant reduction in competitiveness for nodule occupancy [28,39], with mutants that are unable to synthesize PHB exhibiting a much greater loss in competitiveness than those unable to degrade PHB [28], as we have confirmed here.

This is the first study in which the competitiveness of an $S$. meliloti phaZ mutant has been investigated. It was expected, based upon the phenotype of the $b d h A$ mutant [28], that the phaZ mutant would exhibit reduced nodulation competitiveness. Interestingly, the phaZ mutant was as competitive as wild-type in co-inoculation experiments, and consistently out-competed both phaC and bdhA mutants (Table 4). Studies in Azotobacter vinelandii have demonstrated a role for PHB in protection of the cell against environmental stresses including $\mathrm{pH}$, oxidative stress and UV damage [40]. It is conceivable that the enhanced competitiveness of the phaZ mutant, relative to the phaC and $b d h A$ mutants, is due to an enhanced ability to tolerate the conditions encountered in the soil and rhizosphere as a result of the increased cytoplasmic PHB concentration.

Interestingly, the $p h a Z$ mutant shows a similar reduction in long-term survival during starvation to the $p h a C$ mutant (Figure 1). This suggests that the inability to degrade PHB is just as detrimental to the cells as the inability to accumulate it. This also confirms that PHB degradation does play a significant role in fuelling cellular metabolism under adverse conditions, and that glycogen synthesis and degradation is not able to replace the function of PHB metabolism under these conditions.

Previous studies have shown that $S$. meliloti mutants defective in PHB synthesis also exhibit a significant reduction in succinoglycan production under conditions favouring both succinoglycan and PHB production [41], suggesting that these pathways share a common regulatory factor. S. meliloti phaB and phaC mutants exhibit non-mucoid colony morphology on carbon-rich media, while $b d h A$ mutants show a mucoid colony morphology. This study further augments these observations by showing that a phaZ mutant is not only mucoid, but has upregulated exopolysaccharide production relative to the wild-type strain.

Bacteroids of determinate nodules, in contrast to those found in indeterminate nodules, can accumulate up to $50 \%$ of their cellular dry mass as PHB (reviewed in [4]). The synthesis of PHB during symbiosis however, presumably occurs at the expense of symbiotic nitrogen fixation; a theory that is corroborated by the observation that a phaC mutant of $R$. etli demonstrates higher levels of nitrogenase activity relative to wild-type [42]. Bacteroids of indeterminate nodules do not accumulate PHB during symbiosis. It has been suggested [42] that this may be one of the reasons why the $S$. meliloti-alfalfa symbiosis is more effective than that of B. japonicum-soybean or $R$. etli-bean [43]. Interestingly the data presented in this paper suggest that forced accumulation of PHB by $S$. meliloti during symbiosis does not appear to have a negative effect on plant yield, suggesting that PHB synthesis during symbiosis is not the only determinant of symbiotic performance.

\section{Methods}

Bacterial strains, plasmids, growth media and conditions

All bacterial strains and plasmids used are listed in Table 5. Culture methods using Tryptone Yeast (TY), Luria Broth (LB), Yeast Mannitol Broth (YMB), Yeast Mannitol Agar (YMA), and Modified M9 medium supplemented with defined carbon sources, and antibiotic concentrations were carried out as described previously $[23,44]$. 


\section{Genetics and molecular biology techniques}

Bacterial conjugations, $\varphi \mathrm{M} 12$ transductions and homogenotizations were carried out as described previously [22]. DNA manipulations were performed using standard techniques [45]. DNA probes for Southern blot analyses were labelled with digoxygenin (DIG) using the DIG High-Prime Kit (Roche Diagnostics Canada) according to manufacturer's instructions. Southern blots were performed using standard techniques [45]. PCR was carried out by standard techniques [45] using KOD Polymerase (Novagen, Canada).

\section{Construction of exoF::TnphoA fusion}

To generate plasmid-borne exoF::TnphoA fusions, plasmid pD82, a cosmid clone carrying the $S$. meliloti exoF gene and surrounding region of the genome [26], was introduced into the $S$. meliloti exoF::TnphoA fusion strain Rm8369 [27]. This construct was subsequently trans-

Table 5: Bacterial Strains, Plasmids and Phage

\begin{tabular}{|c|c|c|}
\hline Strain or Plasmid & Relevant Characteristics & Reference \\
\hline \multicolumn{3}{|l|}{ S. meliloti } \\
\hline Rm5000 & SU47 rif5 & [22] \\
\hline $\mathrm{Rm} 1021$ & SU47 str-21, Sm $R$ & [50] \\
\hline Rm11105 & Rm1021 phaC 1::Tn5 & [23] \\
\hline Rm11107 & Rm1021 bdhA1::Tn5 & [23] \\
\hline Rm11144 & Rm1021 phaC1::Tn5-233 & [23] \\
\hline Rm11347 & Rm1021 phaB::SSmSp & [24] \\
\hline $\mathrm{Rm} 11417$ & Rm5000 phaZ:: $\Omega S m S p$ & This work \\
\hline Rm11430 & Rm1021 phaZ:: $\Omega S m S p$ & This work \\
\hline Rm8369 & Rm8002 exoF369::TnphoA & [27] \\
\hline \multicolumn{3}{|l|}{ E. coli } \\
\hline $\mathrm{DH} 5 a$ & $\begin{array}{l}\mathrm{F}^{\prime} \text { endA1 hsdR17 }\left(\mathrm{r}_{K} \mathrm{~m}_{+}\right) \text {supE44 } \text { thi }^{-1} \text { recA1 } \\
\text { gyrA Nal }{ }^{R} \text { relA1 } \triangle(\text { (laclZYA-argF) U169 deoR } \\
(\varphi 80 \text { dlac } \Delta(\text { lacZ)M15) }\end{array}$ & {$[51]$} \\
\hline MT607 & pro-82 thi-1 hsdR17 supE44 recA56 & [52] \\
\hline MT616 & MT607 pRK600 & {$[52]$} \\
\hline \multicolumn{3}{|l|}{ Plasmids } \\
\hline pK19mobsacB & Suicide vector $\mathrm{Km}^{R}$ & [53] \\
\hline pGEMTEasy & $\begin{array}{l}\text { Cloning vector for PCR-generated DNA } \\
\text { fragments, } \mathrm{Amp}^{R}\end{array}$ & Promega \\
\hline pAZ101 & $\begin{array}{l}\text { pGEMTeasy carrying } 835 \text { bp fragment of } \\
\text { SMc02770 }\end{array}$ & This work \\
\hline pAZ102 & pAZ101 phaZ::OSmSp & This work \\
\hline pAZ103 & 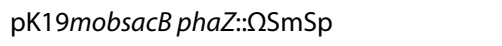 & This work \\
\hline pRK7813 & $\begin{array}{l}\text { RK2 derivative carrying pUC9 polylinker. } \\
\mathrm{Tc}^{R}\end{array}$ & [54] \\
\hline pMA157 & pRK7813 SMc02770 & This work \\
\hline pD82 & $\begin{array}{l}\text { pLAFR } 1 \text { cosmid clone from Rm1021 library } \\
\text { carrying exoF and neighbouring genes }\end{array}$ & {$[26]$} \\
\hline pD82exoF::TnphoA & pD82 exoF::TnphoA & This work \\
\hline \multicolumn{3}{|l|}{ Phage } \\
\hline$\varphi \mathrm{M} 12$ & S. meliloti transducing phage & {$[22]$} \\
\hline
\end{tabular}


ferred into E. coli strain MT607, by triparental conjugation using E. coli strain MT616 as the mobilizer. Transconjugants were selected on LB KmTc, and the nature of the fusion was confirmed by testing for inability to confer YMA mucoidy on the exoF::TnphoA mutant $\mathrm{Rm} 7055$. The resulting construct was named pD82 exoF::TnphoA.

\section{Biochemical assays}

Alkaline phosphatase activity of exoF::TnphoA fusions in S. meliloti strains was measured according to the method of Brinkmann and Beckwith [46]. Cells were grown to an $\mathrm{OD}_{600}$ of $0.7 .1 \mathrm{ml}$ of culture was washed twice in $1 \mathrm{M}$ Tris- $\mathrm{HCl}$ (pH 8.0), and resuspended in $1 \mathrm{ml} 1 \mathrm{M}$ Tris- $\mathrm{HCl}$ $\left(\mathrm{pH}\right.$ 8.0). The $\mathrm{OD}_{600}$ of this cell suspension was then measured. Following a $10 \mathrm{~min}$ equilibration period at $37^{\circ} \mathrm{C}, 50$ $\mu \mathrm{l}$ of $4 \mathrm{mg} / \mathrm{ml} p$-nitrophenyl phosphate (NPP) was added to start the reaction. The reaction was allowed to continue for $11 \mathrm{~min}$ at $37^{\circ} \mathrm{C}$ before being stopped by the addition of $50 \mu \mathrm{l}$ of $1 \mathrm{M} \mathrm{K}_{2} \mathrm{HPO}_{4}$. The cells were pelleted and $50 \mu \mathrm{l}$ of the supernatant was diluted in $450 \mu \mathrm{l}$ of $1 \mathrm{M}$ Tris$\mathrm{HCl}\left(\mathrm{pH}\right.$ 8.0) and $\mathrm{OD}_{420}$ was measured. Units (U) of alkaline phosphatase activity were calculated using the formula:

$$
\mathrm{U}=\frac{1000 \times \mathrm{OD} 600}{\text { Time }(\mathrm{min}) \times \mathrm{OD} 600}
$$

Assuming a molar coefficient of 16,000 for p-nitrophenyl phosphate, $1 \mathrm{U}$ is equal to $0.062 \mathrm{nmol}$ of NPP hydrolyzed per min at a cell $\mathrm{OD}_{600}$ of 1 . Therefore:

$$
\text { nmol NPP hydrolyzed per } \mathrm{min}=\mathrm{U} \times 0.062
$$

For PHB assays, $50 \mathrm{ml}$ cultures were grown at $30^{\circ} \mathrm{C}$ to stationary phase in YMB. Cells were harvested and washed in $0.85 \% \mathrm{NaCl}$ solution before resuspension in 50 $\mathrm{ml} 0.85 \% \mathrm{NaCl}$. PHB was extracted from a $2 \mathrm{ml}$ fraction of this suspension and the remaining $48 \mathrm{ml}$ was used for cell dry weight determination by incubation of the pellet at $60^{\circ} \mathrm{C}$ until the pellet was dry and no further loss in mass was recorded. PHB content was measured by the method of Law and Slepecky [47] and expressed as a percentage of total cell dry weight. All glassware was washed in hot chloroform and rinsed in ethanol before use, to eliminate plasticizers. A standard curve was constructed by dissolving known quantities of PHB (Sigma) in hot chloroform to a final volume of $1 \mathrm{ml}$. The chloroform was allowed to evaporate before addition of $10 \mathrm{ml}$ of $\mathrm{H}_{2} \mathrm{SO}_{4}$ and PHB was processed as described elsewhere [47].

\section{Carbon starvation assay}

Saturated TY cultures were washed twice to remove traces of nutrients, and were subcultured 1:50 into carbon-free M9 medium. These cultures were incubated at $30^{\circ} \mathrm{C}$, shaking at $180 \mathrm{rpm}$. Viable cell counts were monitored at weekly intervals by plating on TY agar. Samples at $t=0$ were each given a relative value of 1 , and all subsequent samples are compared to this starting value. Values recorded are the means from triplicate cultures.

\section{Nodulation studies}

Medicago sativa cv. Iroquois seeds were surface-sterilized in $95 \%$ ethanol for 2 min followed by $15 \mathrm{~min}$ in $0.5 \%$ sodium hypochlorite. After several washes in sterile $\mathrm{dH} 2 \mathrm{O}$, seeds were germinated in the dark on sterile water agar plates at room temperature for approximately 36 hours. Seedlings were transferred to modified Leonard assemblies containing sterilized vermiculite soaked in Jensen's N-free plant nutrient solution [48]. Five seedlings were planted in each jar and inoculated with $5 \mathrm{ml}$ of 1:50 dilution of saturated TY culture. The assemblies were placed in a growth chamber (Conviron CMP3244, Model \# EF7, Controlled Environments Ltd., Winnipeg) with 16 h, $25^{\circ} \mathrm{C}$ day $/ 8 \mathrm{~h}, 20^{\circ} \mathrm{C}$ night and light intensity of 300 $\mu$ moles $\mathrm{m}^{-2} \mathrm{~s}^{-1}$. For shoot dry weight determination, plants were harvested approximately 5 weeks post-inoculation and the shoots separated from the roots. The shoots were transferred to brown paper bags and incubated at $60^{\circ} \mathrm{C}$ until no further loss in mass was recorded. Shoot dry weight is expressed as $\mathrm{mg}^{-1}$ plant $^{-1}$. Nodule occupancy competitiveness was assayed in modified Leonard assemblies as described above. Inoculants consisted of wildtype and mutant cultures mixed in 1:1 and 1:9 ratios, or mutant cultures mixed in a 1:1 ratio. Plants were harvested four weeks post-inoculation and nodules were collected. Nodules were surface-sterilized with $1 \%$ sodium hypochlorite (15 $\mathrm{min})$, washed twice with $\mathrm{LB}$, and then squashed in a few drops of TY containing $0.3 \mathrm{M}$ sucrose. The resultant suspension was streaked on TY. Four colonies isolated from each nodule were screened for the appropriate antibiotic-resistance marker. The bacterial population within each nodule was thus scored as either consisting of one strain or a mixture of two strains.

\section{Electron microscopy}

M. sativa plants were harvested 28-30 days post-infection. Roots were washed to remove traces of vermiculite, and the nodules were transferred into primary fixative (4\% formaldehyde, $1 \%$ glutaraldehyde in $80 \mathrm{mM}$ HEPES $\mathrm{pH} 7.0)$ and cut into small pieces. The samples were subjected to 4 cycles of vacuum infiltration ( 2 mins per cycle) and were left overnight at $4^{\circ} \mathrm{C}$. Following infiltration, the nodules were washed thoroughly in sterile water, and 
stained for 4 hours in $1 \% \mathrm{OsO}_{4}$. The nodules were washed again in water and dehydrated through a gradient of acetone. The nodules were embedded in epon araldite resin and transferred to BEEM capsules for 48 hours at $60^{\circ} \mathrm{C}$. Ultrathin sections were cut using a Reichert Ultracut E microtome, and were stained with uranyl acetate and lead citrate using standard techniques [49]. Samples were analyzed in a Philips CM10 transmission electron microscope at an accelerating voltage of $60 \mathrm{kV}$.

\section{Authors' contributions}

AZ generated the phaZ mutant. MAT performed the cloning reactions, carbon starvation assays, symbiosis assays, electron microscopy, supervised KNL and drafted the manuscript. KNL conducted carbon starvation assays. TCC constructed the pD82exoF::TnphoA vector. DC conducted the alkaline phosphatase assays and plant competition experiments. TCC and SRDC participated in experimental design and data analysis. All authors have read and approved the final manuscript.

\section{Acknowledgements}

We acknowledge funding from the NSERC Discovery Grant Program, NSERC CRD Program, and EMD CropBioscience. MAT was supported by an NSERC IPS Fellowship. A special thank you is extended to Dale Weber for his assistance with the electron microscopy and to Nameera Chagpar for her help in the laboratory.

\section{Author Details}

'Department of Biology, University of Waterloo, 200 University Ave W, Waterloo, ON N2L 3G1, Canada, ${ }^{2}$ Current address: Council of Canadian Academies, 180 Elgin St, Suite 1401, Ottawa, ON, K2P 2K3, Canada, ${ }^{3}$ Current address: Department of Biology, McMaster University, 1280 Main St West, Hamilton, ON, L8S 4K1, Canada and ${ }^{4}$ Current address: Department of Molecular Genetics, University of Toronto, 1 King's College Circle, Toronto, ON, M5S 1A8, Canada

Received: 19 December 2009 Accepted: 27 March 2010

Published: 27 March 2010

\section{References}

1. Ronson C, Lyttleton P, Robertson J: $\mathrm{C}_{4}$-dicarboxylate transport mutants of Rhizobium trifolii form ineffective nodules on Trifolium repens. Proc Natl Acad Sci USA 1981, 78:4284-4288.

2. Salminen S, Streeter J: Labeling of carbon pools in Bradyrhizobium japonicum and Rhizobium leguminosarum bv viciae bacteroids following incubation of intact nodules with C14. Plant Physiol 1992, 100:597-604.

3. Finan T, Wood J, Jordan D: Symbiotic properties of $\mathrm{C}_{4}$-dicarboxylic acid transport mutants of Rhizobium leguminosarum. J Bacteriol 1983, 154:1403-1413.

4. Trainer MA, Charles TC: The role of PHB metabolism in the symbiosis of rhizobia with legumes. Appl Microbiol Biotechnol 2006, 71(4):377-86. [0175-7598 (Print) Journal Article Review]

5. Craig A, Williamson K: Three inclusions of rhizobial bacteroids and their cytochemical character. Arch Microbiol 1972, 87:165-171.

6. Goodchild D, Bergerson F: Electron microscopy of the infection and subsequent development of soybean nodule cells. J Bacterio/ 1966, 92:204-213

7. Zevenhuizen L: Cellular glycogen, B-1,2-glucan-poly-B-hydroxybutyric acid and extracellular polysaccharides in fast-growing species of Rhizobium. Antonie van Leeuwenhoek 1981, 47:481-497.

8. Hirsch AM, Long S, Bang M, Haskins N, Ausubel F: Structural studies of alfalfa roots infected with nodulation mutants of Rhizobium meliloti. J Bacteriol 1982, 151:411-419.

9. Hirsch AM, Bang M, Ausubel FM: Ultrastructural analysis of ineffective alfalfa nodules formed by nif::Tn 5 mutants of Rhizobium meliloti. $J$ Bacteriol 1983, 155:367-380.

10. Mergaert $P$, Uchiumi T, Alunni B, Evanno G, Cheron A, Catrice O, Mausset AE, Barloy-Hubler F, Galibert F, Kondorosi A, Kondorosi E: Eukaryotic control on bacterial cell cycle and differentiation in the Rhizobiumlegume symbiosis. Proc Natl Acad Sci USA 2006, 103(13):5230-5235.

11. Lodwig E, Hosie A, Bourdes A, Findlay K, Allaway D, Karunakaran R, Downie J, Poole P: Amino-acid cycling drives nitrogen fixation in the legumeRhizobium symbiosis. Nature 2003, 422:722-726.

12. Abe T, Kobayashi T, Saito T: Properties of a novel intracellular poly(3hydroxybutyrate) depolymerase with high specific activity (PhaZd) in Wautersia eutropha H16. J Bacteriol 2005, 187(20):6982-6990.

13. Saegusa H, Shiraki M, Kanai C, Saito T: Cloning of an intracellular Poly-3Hydroxybutyrate depolymerase gene from Ralstonia eutropha $\mathrm{H} 16$ and characterization of the gene product. J Bacterio/ 2001, 183:94-100.

14. Tseng CL, Chen HJ, Shaw GC: Identification and characterization of the Bacillus thuringiensis phaZ gene, encoding new intracellular poly-3hydroxybutyrate depolymerase. J Bacterio/ 2006, 188(21):7592-7599.

15. Gao D, Maehara A, Yamane T, Ueda S: Identification of the intracellular polyhydroxyalkanoate depolymerase gene of Paracoccus denitrificans and some properties of the gene product. FEMS Microbiol Lett 2001, 196(2):159-164

16. Kobayashi T, Nishikori K, Saito T: Properties of an intracellular poly(3hydroxybutyrate) depolymerase (PhaZ1) from Rhodobacter spheroides. Curr Microbiol 2004, 49(3):199-202.

17. Kadouri $D$, Jurkevitch $E$, Okon $Y$ : Poly beta-hydroxybutyrate depolymerase (PhaZ) in Azospirillum brasilense and characterization of a phaZ mutant. Arch Microbiol 2003, 180(5):309-318.

18. Dixon R: The origin of the membrane surrounding the bacteria and bacteroids and the presence of glycogen in clover root nodules. Arch Microbiol 1967, 56:156-166.

19. Layzell D, Hunt S, Palmer G: Mechanism of nitrogenase inhibition in soybean nodules. Pulse-modulated spectroscopy indicates that nitrogenase acitivity as limited by $\mathrm{O}_{2}$. Plant Physiol 1990, 92:1101-1107.

20. Galibert F, Finan TM, Long SR, Puhler A, Abola P, Ampe F, Barloy-Hubler F, Barnett MJ, Becker A, Boistard P, Bothe G, Boutry M, Bowser L, Buhrmester J, Cadieu E, Capela D, Chain P, Cowie A, Davis RW, Dreano S, Federspiel NA, Fisher RF, Gloux S, Godrie T, Goffeau A, Golding B, Gouzy J, Gurjal M, Hernandez-Lucas I, Hong A, Huizar L, Hyman RW, Jones T, Kahn D, Kahn ML, Kalman S, Keating DH, Kiss E, Komp C, Lelaure V, Masuy D, Palm C, Peck MC, Pohl TM, Portetelle D, Purnelle B, Ramsperger U, Surzycki R, Thebault P, Vandenbol M, Vorholter FJ, Weidner S, Wells DH, Wong K, Yeh $\mathrm{KC}$, Batut J: The composite genome of the legume symbiont Sinorhizobium meliloti. Science 2001, 293(5530):668-72.

21. Jaeger KE, Ransac S, Dijkstra BW, Colson C, van Heuvel M, Misset O Bacterial lipases. FEMS Microbiol Rev 1994, 15:29-63.

22. Finan TM, Hartwieg E, LeMieux K, Bergman K, Walker G, Signer E: General transduction in Rhizobium meliloti. J Bacteriol 1984, 159:120-124.

23. Charles TC, Cai GQ, Aneja P: Megaplasmid and chromosomal loci for the PHB degradation pathway in Rhizobium (Sinorhizobium) meliloti. Genetics 1997, 146(4):1211-20. [0016-6731 (Print) Journal Article]

24. Aneja P, Dai M, Lacorre DA, Pillon B, Charles TC: Heterologous complementation of the exopolysaccharide synthesis and carbon utilization phenotypes of Sinorhizobium meliloti Rm1021 polyhydroxyalkanoate synthesis mutants. FEMS Microbiol Lett 2004, 239(2):277-83. [0378-1097 (Print) Journal Article]

25. Reuber TL, Walker GC: Biosynthesis of succinoglycan, a symbiotically important exopolysaccharide of Rhizobium meliloti. Cell 1993, 74(2):269-80. [0092-8674 (Print) Comparative Study Journal Article Research Support, Non-U.S. Gov't Research Support, U.S. Gov't, Non-P.H.S. Research Support, U.S. Gov't, P.H.S.]

26. Leigh JA, Signer ER, Walker GC: Exopolysaccharide-deficient mutants of Rhizobium meliloti that form ineffective nodules. Proc Natl Acad Sci USA 1985, 82(18):6231-5. [0027-8424 (Print) Journal Article Research Support, Non-U.S. Gov't Research Support, U.S. Gov't, P.H.S.]

27. Long S, McCune S, Walker GC: Symbiotic loci of Rhizobium melilot identified by random Tn phoA mutagenesis. J Bacteriol 1988, 170(9):4257-65.

28. Aneja P, Zachertowska A, Charles TC: Comparison of the symbiotic and competition phenotypes of Sinorhizobium meliloti PHB synthesis and degradation pathway mutants. Can J Microbio/ 2005, 51(7):599-604.

29. Gonzalez JE, York GM, Walker GC: Rhizobium meliloti exopolysaccharides: synthesis and symbiotic function. Gene 1996, 179:141-146.

30. Miyake M, Kataoka K, Shirai M, Asada Y: Control of poly- $\beta$ hydroxybutyrate synthase mediated by acetyl phosphate in 
cyanobacteria. J Bacteriol 1997, 179(16):5009-13. [0021-9193 (Print) Journal Article]

31. McCleary WR, Stock JB, Ninfa AJ: Is acetyl phosphate a global signal in Escherichia coli? J Bacteriol 1993, 175(10):2793-2798.

32. Klein AH, Shulla A, Reimann SA, Keating DH, Wolfe AJ: The intracellular concentration of acetyl phosphate in Escherichia coli is sufficient for direct phosphorylation of two-component response regulators. Bacteriol 2007, 189(15):5574-5581.

33. Van Elsas J, van Overbeek LS: Starvation in bacteria: Bacterial responses to soil stimuli Plenum Press, New York; 1993.

34. Kadouri D, Jurkevitch E, Okon Y: Involvement of the Reserve Material Poly-b-Hydroxybutyrate in Azospirillum brasilense stress endurance and root colonization. Appl Environ Microbiol 2003, 69:3244-3250.

35. Lopez N, Floccari M, Garcia A, Steinbuchel A, Mendez B: Effect of poly(3hydroxybutyrate) (PHB) content on the starvation survival of bacteria in natural waters. FEMS Microbiol Ecol 1995, 16:95-102.

36. Ruiz JA, Lopez NI, Fernandez RO, Mendez BS: Polyhydroxyalkanoate degradation is associated with nucleotide accumulation and enhances stress resistance and survival of Pseudomonas oleovorans in natural water microcosms. Appl Environ Microbiol 2001, 67:225-30. [0099-2240 (Print) Journal Article]

37. Tal S, Okon Y: Production of the reserve material poly-3hydroxybutyrate and its function in Azospirillum brasilense. Can $J$ Microbiol 1985, 31:608-613.

38. Dawes E: Microbial energy reserve compounds Glasgow: Blackie and Son Itd; 1986:145-165.

39. Willis $L$, Walker G: The $p h b C$ (poly-b-hydroxybutyrate synthase) gene of Rhizobium (Sinorhizobium) meliloti and characterization of phbC mutants. Can J Microbiol 1998, 44(6):554-564.

40. Okon Y, Itzigsohn R: Poly- $\beta$-hydroxybutyrate metabolism in Azospirillum brasilense and the ecological role of PHB in the rhizosphere. FEMS Microbiol Lett 1992, 103:131-139.

41. Povolo S, Tombolini R, Morea A, Anderson A, Casella S, Nuti M: Isolation and characterization of mutants of Rhizobium meliloti unable to synthesize poly-3-hydroxybutyrate (PHB). Can J Microbio/ 1994, 40:823-829.

42. Cevallos M, Encarnacion S, Leija A, Mora Y, Mora J: Genetic and physiological characterization of a Rhizobium etli mutant strain unable to synthesize poly-beta-hydroxybutyrate. J Bacteriol 1996, 178(6):1646-1654

43. Hardason G: Methods for measuring biological nitrogen fixation in grain legumes. Plant and Soil 1993, 152:1-17.

44. Charles TC, Finan TM: Analysis of a 1600-kilobase Rhizobium meliloti megaplasmid using defined deletions generated in vivo. Genetics 1991, 127:5-20

45. Sambrook JRD: Molecular Cloning: a laboratory manual 3rd edition. Cold Spring Harbor, NY: Cold Spring Harbor Laboratory; 2001.

46. Brinkmann E, Beckwith J: Analysis of the regulation of Escherichia coli alkaline phosphatase synthesis using deletions and $\varphi 80$ transducing lysates. J Mol Biol 1975, 96:307-316.

47. Law J, Slepecky R: Assay of poly-3-hydroxybutyric acid. J Bacteriol 1961, 82:33-36.

48. Jensen H: Nitrogen fixation in leguminous plants. I. General characters of root-nodule bacteria isolated from species of Medicago and Trifolium in Australia. Australia Proc Linn Soc NSW 1942, 66:98-108.

49. Venable JH, Coggeshall R: A Simplified Lead Citrate Stain for Use in Electron Microscopy. J Cell Biol 1965, 25:407-8. [0021-9525 (Print) Journal Article]

50. Meade HM, Long SR, Ruvkun GB, Brown SE, Ausubel FM: Physical and genetic characterization of symbiotic and auxotrophic mutants of Rhizobium meliloti induced by transposon Tn 5 mutagenesis. J Bacteriol 1982, 149:114-22. [0021-9193 (Print) Journal Article]

51. Hanahan D: Studies on transformation of Escherichia coli with plasmids. J Mol Biol 1983, 166(4):557-80. [0022-2836 (Print) Journal Article]

52. Finan TM, Kunkel B, De Vos GF, Signer ER: Second symbiotic megaplasmid in Rhizobium meliloti carrying exopolysaccharide and thiamine synthesis genes. J Bacteriol 1986, 167:66-72. [0021-9193 (Print) Journal Article]

53. Schafer A, Tauch A, Jager W, Kalinowski J, Thierbach G, Puhler A: Small mobilizable multi-purpose cloning vectors derived from the Escherichia coli plasmids pK18 and pK19: selection of defined deletions in the chromosome of Corynebacterium glutamicum. Gene 1994, 145:69-73.

54. Jones JD, Gutterson N: An efficient mobilizable cosmid vector, pRK7813, and its use in a rapid method for marker exchange in Pseudomonas fluorescens strain HV37a. Gene 1987, 61(3):299-306.

doi: $10.1186 / 1471-2180-10-92$

Cite this article as: Trainer et al, Identification and characterization of the intracellular poly-3-hydroxybutyrate depolymerase enzyme PhaZ of Sinorhizobium meliloti BMC Microbiology 2010, 10:92

\section{Submit your next manuscript to BioMed Central} and take full advantage of:

- Convenient online submission

- Thorough peer review

- No space constraints or color figure charges

- Immediate publication on acceptance

- Inclusion in PubMed, CAS, Scopus and Google Scholar

- Research which is freely available for redistribution 